\title{
The growing pre-mRNA recruits actin and chromatin-modifying factors to transcriptionally active genes
}

\author{
Mikael Sjölinder, ${ }^{1}$ Petra Björk, ${ }^{1}$ Emilia Söderberg, ${ }_{1}^{1}$ Nafiseh Sabri, ${ }^{1,3}$ Ann-Kristin Östlund Farrants, ${ }^{2}$ \\ and Neus Visa ${ }^{1,4}$ \\ ${ }^{1}$ Department of Molecular Biology and Functional Genomics, ${ }^{2}$ Department of Zoological Cell Biology, The Wenner-Gren \\ Institute, Stockholm University, SE-10691 Stockholm, Sweden
}

\begin{abstract}
In the dipteran Chironomus tentans, actin binds to hrp65, a nuclear protein associated with mRNP complexes. Disruption of the actin-hrp65 interaction in vivo by the competing peptide 65-2CTS reduces transcription drastically, which suggests that the actin-hrp65 interaction is required for transcription. We show that the inhibitory effect of the 65-2CTS peptide on transcription is counteracted by trichostatin A, a drug that inhibits histone deacetylation. We also show that actin and hrp65 are associated in vivo with p2D10, an evolutionarily conserved protein with histone acetyltransferase activity that acts on histone $H 3$. p2D10 is recruited to class II genes in a transcription-dependent manner. We show, using the Balbiani ring genes of $C$. tentans as a model system, that p2D10 is cotranscriptionally associated with the growing pre-mRNA. We also show that experimental disruption of the actin-hrp65 interaction by the 65-2CTS peptide in vivo results in the release of p2D10 from the transcribed genes, reduced histone $\mathrm{H} 3$ acetylation, and a lower level of transcription activity. Furthermore, antibodies against p2D10 inhibit run-on elongation. Our results suggest that actin, hrp65, and p2D10 are parts of a positive feedback mechanism that contributes to maintaining the active transcription state of a gene by recruiting HATs at the RNA level.
\end{abstract}

[Keywords: Histone acetylation; Chironomus tentans; hrp65; nuclear actin; TFIIIC]

Received February 4, 2005; revised version accepted June 8, 2005.

Studies in the last few decades have provided detailed molecular information about the basal transcription machinery responsible for the expression of protein-coding genes. Our knowledge of the transcription process is such that transcription of DNA templates can be carried out in vitro using purified components (for review, see Li et al. 1996; Kadonaga 2004). Transcription of natural templates in the living cell is far more complex, due to the packaging of DNA templates into chromatin, a highly organized nucleoprotein assembly that can regulate the access of the transcription machinery to the DNA (for review, see Kornberg and Lorch 1999; Khorasanizadeh 2004). Two different types of mechanism have been identified that modify chromatin structure and regulate chromatin access: covalent histone modification and ATP-dependent chromatin remodeling (for review, see Narlikar et al. 2002). There are different types of covalent histone modification that affect the N-terminal sequences of core histones. Some of these modifica-

${ }^{3}$ Present address: Department of Developmental Biology, The WennerGren Institute, Stockholm University, SE-10691 Stockholm, Sweden. ${ }^{4}$ Corresponding author.

E-MAIL neus.visa@molbio.su.se; FAX 46-8-16-6488.

Article and publication are at http://www.genesdev.org/cgi/doi/10.1101/ gad.339405. tions affect the degree of chromatin compaction and play a central role in the regulation of gene expression (for review, see Jenuwein and Allis 2001). For instance, acetylation of lysine residues in the histone tails disrupts DNA-histone interactions by neutralizing positively charged residues, which results in a more open chromatin conformation that is compatible with transcription. Histones acetylated at specific residues may also serve as specific landmarks that are recognized by ATP-dependent chromatin-remodeling factors, in addition to the direct effect that histone acetylation may have on chromatin structure (Jenuwein and Allis 2001).

The transcription machinery interacts with factors involved in downstream events, such as pre-mRNA processing and export (for review, see Maniatis and Reed 2002; Proudfoot et al. 2002), and this introduces an additional level of complexity into the transcription of natural templates in the living cell. These interactions facilitate cotranscriptional pre-mRNA processing by recruiting pre-mRNA processing factors to the growing pre-mRNA (for review, see Neugebauer 2002). Recent results suggest that the interactions between the transcriptional and processing machineries are reciprocal: not only does the transcription machinery facilitate the recruitment of processing factors to the pre-mRNA, but 
also some processing factors interact with the transcription machinery, regulating its activity (for review, see Manley 2002; Jensen et al. 2003; Zorio and Bentley 2004). For instance, the U1 snRNP interacts with TFIIH and stimulates transcription initiation in vitro (Kwek et al. 2002). Interestingly, the effect of U1 snRNP on TFIIH depends on the presence of an intron in the template, which suggests that the effect of U1 snRNP on transcription requires binding of U1 snRNP to the growing premRNA. It has been suggested that pre-mRNA plays a role in the recruitment of factors that affect the transcription process in the dipteran Chironomus tentans. A complex between the mRNP-associated protein hrp65 and actin regulates transcription at the elongation level in C. tentans (Percipalle et al. 2003). Isoform 2 of the hrp65 protein (hrp65-2) is a nuclear protein that binds to actin, and a peptide that competes with hrp65-2, disrupting the interaction between actin and hrp65-2, globally inhibits transcription in cells. Furthermore, immunoelectron microscopy (immuno-EM) experiments have shown that both hrp65-2 and actin bind to the premRNA cotranscriptionally (Percipalle et al. 2001, 2003), which suggests that these proteins influence transcription from their location on the premessenger ribonucleoprotein complexes (pre-mRNPs).

hrp65 belongs to a family of evolutionarily conserved proteins that includes the mammalian proteins PSF, p54 ${ }^{\mathrm{nrb}} / \mathrm{NonO}$, and PSP1, and the Drosophila protein NonA/Bj6 (for review, see Shav-Tal and Zipori 2002). These proteins are involved in several gene expression processes, including splicing, the retention of edited RNAs of viral origin in the nucleus, and transcription regulation. In particular, PSF and $\mathrm{p} 54^{\mathrm{nrb}} / \mathrm{NonO}$ bind to the C-terminal domain of RNA polymerase II (Pol II) (Emili et al. 2002), and the PSF-p54 ${ }^{\text {nrb }} /$ NonO complex acts as a coregulator in steroidogenic gene transcription (Sewer and Waterman 2002; Ishitani et al. 2003). PSF can interact with Sin3A and mediate transcriptional silencing by recruiting histone deacetylases (HDACs) to promoters regulated by nuclear hormone receptors (Mathur et al. 2001).

Actin is associated with (pre)mRNPs in the cell nucleus (for review, see Bettinger et al. 2004), and several chromatin-remodeling complexes in yeast, insects, and mammals contain actin and actin-related proteins (for review, see Olave et al. 2002). Furthermore, recent reports have strengthened the view that actin plays an indispensable role in transcription (for review, see Visa 2005), not only at the chromatin level but also in the assembly of preinitiation complexes (Hofmann et al. 2004; Hu et al. 2004; Philimonenko et al. 2004).

Orthologs of actin and of the mammalian hrp65, PSF, and $\mathrm{p} 54^{\mathrm{nrb}} / \mathrm{NonO}$ may play a role in regulating transcription through chromatin remodeling. This raises the possibility that the transcriptional inhibition observed in $C$. tentans when the interaction between actin and hrp65 is disrupted is due to alterations at the chromatin level. We have looked for chromatin-remodeling factors associated with actin and with hrp65, and we have focused our attention on a TFIIIC220-like protein of $C$. tentans named
"p2D10" (Sabri et al. 2002). The p2D10 protein is associated with hrp65 and is present in RNA-containing complexes in vivo (Sabri et al. 2002). The human p2D10 ortholog, TFIIIC220, has histone acetyltransferase (HAT) activity (Kundu et al. 1999), while the yeast TFIIIC plays a direct role in remodeling chromatin on the U6 snRNA gene in Saccharomyces cerevisiae (Shivaswamy et al. 2004). These observations led us to investigate whether p2D10 plays a role in the regulation of the chromatin structure.

\section{Results}

p2D10, a TFIIIC220 homolog, is recruited to loci transcribed by RNA polymerase II in a transcription-dependent manner

The p2D10 protein was initially identified in C. tentans (Sabri et al. 2002). BLAST searches and sequence analysis have revealed that p2D10 is structurally similar to the largest subunit of the general transcription factor TFIIIC2. The p2D10 protein shares $23 \%$ identity and $42 \%$ similarity with human TFIIIC220. Although the overall degree of conservation is not high at the amino acid level, iterative PSI-BLAST studies have identified common domains with conserved sequences among all the eukaryotic B-block-binding subunits, including $C$. tentans p2D10 (Matsutani 2004). Despite its similarity to a component of the RNA polymerase III (Pol III) machinery, p2D10 coimmunoprecipitates with several proteins involved in mRNA biogenesis (Sabri et al. 2002). We have confirmed that p2D10 is involved in the expression of class II genes by staining preparations of polytene chromosomes of $C$. tentans with antibodies against $\mathrm{p} 2 \mathrm{D} 10$, and determining that $\mathrm{p} 2 \mathrm{D} 10$ is present in the Balbiani ring (BR) gene loci (Fig. 1). The BR genes code for large secretory proteins of the salivary glands and large chromosomal puffs (known as "BR"s) form when these genes are transcribed (for review, see Wieslander 1994). The BR pre-mRNAs have all the features of typical protein-coding transcripts and are a useful experimental system for in situ studies of mRNA biogenesis (for review, see Daneholt 2001). The BR genes can be easily identified in polytene chromosome preparations, and the association of specific proteins with the growing BR premRNA can be studied by immunolabeling polytene chromosomes. Three BR puffs on chromosome IV are active under normal physiological conditions, and all three were stained by the anti-p2D10 antibodies (Fig. 1). Additional bands corresponding to other gene loci were also stained (arrows in Fig. 1). The same pattern of staining as that shown in Figure 1 was obtained with two independent $\mathrm{mAbs}$ and one peptide-specific rabbit antibody against p2D10. Omission of the primary antibody totally abolished the labeling (data not shown).

BR6, an inducible BR puff located on chromosome III, can be activated by feeding the $C$. tentans larvae galactose (Beermann 1973). p2D10 was not stained at the BR6 locus under normal feeding conditions, when the BR6 gene is silent. However, the locus was intensely stained 

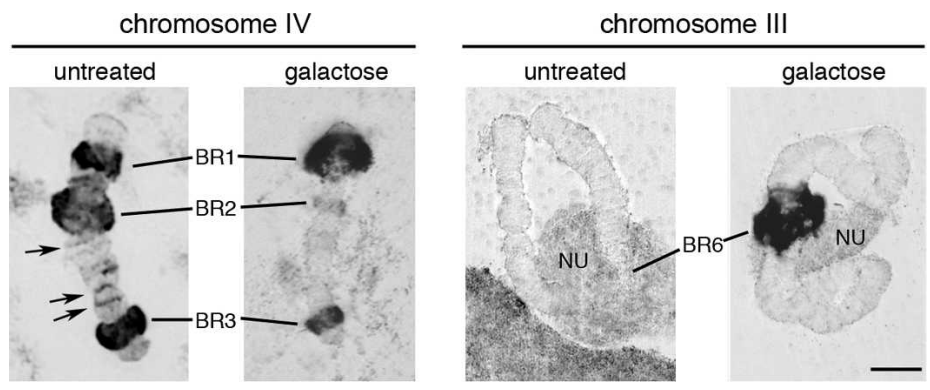

Figure 1. Association of p2D10 with class II genes. Polytene chromosome squashes from untreated larvae and from larvae grown in the presence of galactose were immunostained with the anti-p2D10 mAb 1F2. In untreated chromosomes, the antibody stained the active BR1, BR2, and BR3 gene loci on chromosome IV, and it stained other loci in the polytene chromosomes (arrows). This pattern shows that p2D10 is located at transcriptionally active class II genes. Feeding the larvae with galactose induced the expression of the BR6 gene on chromosome III and the recruitment of p2D10 to the activated BR6 locus. The galactose treatment also reduced the transcriptional activity at the BR2 locus, and this was accompanied by a decrease in the p2D10 signal at this site (cf. the staining at BR2 in untreated and galactose). The micrographs were taken under bright-field conditions. (BR) Balbiani ring; (NU) nucleolus. The scale bar represents $\sim 10 \mu \mathrm{m}$.

for p2D10 following galactose treatment of the larvae, when the BR6 gene was active (Fig. 1). The galactose treatment represses the BR2 puff (Beermann 1973), and immunostaining at the BR2 locus was, indeed, lower in galactose-treated larvae (Fig. 1). We conclude that p2D10 is associated with loci transcribed by Pol II, and that the presence of p2D10 at such loci is correlated with transcriptional activity.

\section{p2D10 is associated with growing transcripts}

The synthesis of the BR pre-mRNA and its assembly into RNP particles can be visualized using transmission EM. We carried out immuno-EM experiments to establish the precise location of $\mathrm{p} 2 \mathrm{D} 10$ in the active BR transcription units. Salivary glands were fixed and cryosectioned, and the sections were incubated with anti-p2D10 mAbs and with a gold-conjugated secondary antibody. In EM preparations, the active $\mathrm{BR}$ genes appear as chromatin loops with a central axis, the transcribed chromatin template, decorated with growing pre-mRNPs (Fig. 2A). The active BR genes show a distinct polarity defined by the size and the structure of the growing pre-mRNPs along the transcription unit (Skoglund et al. 1983). Full-length genes are not found in the sections used for EM, but partial segments can be assigned to defined positions along the gene, based on the morphology of the growing premRNPs. In the proximal (p) portion of the BR gene, the growing BR transcripts are packed into pre-mRNP fibers of increasing length. In the middle $(\mathrm{m})$ and distal $(\mathrm{d})$ portions, the $5^{\prime}$ domain of the growing pre-mRNP particles becomes packed into a dense globular structure and the pre-mRNPs appear as stalked granules of increasing diameter (Fig. 2A,B).

We were able to map the binding of p2D10 to the proximal $(\mathrm{p})$, middle $(\mathrm{m})$, and distal (d) segments of the BR gene, since we could identify the different parts of the BR transcription unit. Figure $2 \mathrm{~B}$ and $\mathrm{C}$ shows that $\mathrm{p} 2 \mathrm{D} 10$ was present in all three segments of the transcribed BR gene, with a higher concentration in the proximal segments. Interestingly, the distribution of p2D10 correlated with the distribution of hrp65-2, previously reported by Percipalle et al. (2003). The immuno-EM results allow us to conclude that p2D10 is located along the entire BR gene.
The distal BR pre-mRNPs are large enough to allow us to discriminate between DNA-bound labeling and RNPbound labeling. This allowed us to determine whether p2D10 was associated with the DNA axis or with the growing pre-mRNP in the transcribed BR genes. We determined whether the gold markers were close to the DNA axis (within $25 \mathrm{~nm}$ from the axis) or distant from the axis (>25 nm from the axis). This latter group contains only gold markers associated with BR pre-mRNP, whereas the markers close to the axis may be p2D10 molecules bound to the stalk of the growing pre-mRNP particles, bound to chromatin, or bound to the transcription machinery. Figure 2D shows that some gold markers were distant from the axis and some were close to the axis. We conclude that a fraction of p2D10 is incorporated cotranscriptionally into the growing $\mathrm{BR}$ premRNPs. There is also a fraction of p2D10 close to the BR chromatin, although we cannot establish whether this latter fraction is bound to DNA or to RNA.

We also analyzed whether the association of p2D10 with the transcribed genes was disrupted by RNase treatment. We chose to use whole-mount salivary gland preparations rather than the chromosome squashes shown in Figure 1, since the whole mounts are more sensitive and provide more comprehensive information about the general distribution of p2D10 in the nuclei of the salivary gland cells in vivo. Salivary glands were permeabilized and incubated in the presence of RNase A for $30 \mathrm{~min}$ before immunofluorescent staining with an antip2D10 antibody. Figure 2E shows that the intensity of the immunofluorescent signal in the chromosomes was reduced by the RNase A digestion, which confirms that the association of p2D10 with the chromosomes is mediated by RNA.

\section{p2D10 has histone acetyltransferase activity}

The location of p2D10 in the transcribed BR genes is compatible with a mechanism in which p2D10 acts on the BR chromatin template. The human TFIIIC220 has HAT activity (Kundu et al. 1999), and the yeast TFIIIC complex is involved in chromatin remodeling at the U6 snRNA gene (Shivaswamy et al. 2004). This led us to examine whether p2D10 can also function as a HAT. Endogenous p2D10 from C. tentans tissue culture cells 
Sjölinder et al.

was isolated by immunoprecipitation and tested for acetyltransferase activity using either histones or bovine serum albumin (BSA) as substrate and ${ }^{3} \mathrm{H}$-acetyl CoA as the source of acetyl groups. The immunoisolated p2D10 protein catalyzed histone acetylation, but acetylated BSA at the same level as background (Fig. 3A). The HAT activity in control experiments in which no antibody was present was at the same level as the background.

Next, the nuclear extracts were denatured with urea before immunoprecipitation in order to disrupt proteinprotein interactions. This allowed us to rule out the possibility that the HAT activity that we detected originated from coimmunoprecipitated proteins and not from p2D10 itself. Western blot analysis confirmed that the interaction between $\mathrm{p} 2 \mathrm{D} 10$ and some of its binding partners was disrupted by urea (data not shown). The HAT activity of p2D10 remained higher than background when p2D10 was immunoprecipitated from urea-treated extracts. This supports the conclusion that the HAT activity that we detected arose from p2D10 itself. The reduction in activity that occurred after urea treatment may be due to partial denaturation of p2D10 or to dissociation of cofactors.

In another series of control experiments, immunoprecipitation with antibodies against hrp65 yielded significant HAT activity that was lost in urea-treated extracts

Figure 2. p2D10 is associated with growing BR pre-mRNP particles. (A) Schematic representation of the active BR transcription unit illustrating the distinct morphology of the growing pre-mRNPs in the proximal $(\mathrm{p})$, middle $(\mathrm{m})$, and distal (d) portions of the BR gene. $(B)$ Immuno-EM analysis of p2D10 distribution in the active BR transcription unit. Thin cryosections of aldehyde-fixed salivary glands were immunolabeled with antip2D10 mAbs, either 2D10 or 1F2, and detected with a secondary antibody conjugated to colloidal gold markers. The left panel shows a section of a salivary gland cell nucleus immunostained with anti-p2D10 antibodies showing the different portions of a BR gene as visualized in the EM. The right panel shows a schematic interpretation of the micrograph. The bar represents $200 \mathrm{~nm} .(C)$ The histogram shows the distribution of p2D10 along the active BR gene obtained with two independent mAbs against p2D10, mAb 2D10 and mAb 1F2. For each antibody, the numbers of immuno-gold markers located in each portion of the BR gene were counted, and the distribution of labeling was expressed as percentage of immuno-gold markers in each portion of the gene. The number of gold markers analyzed was $n=402$ for $\mathrm{mAb} 2 \mathrm{D} 10$ and $n=1730$ for mAb 1F2. The distribution of hrp65-2, based on data from Percipalle et al. (2003), is also presented for comparison. (D) Four examples of immunolabeling in growing BR pre-mRNP particles at higher magnification. Note the association of immuno-gold markers with the growing BR pre-mRNP particles. Schematic interpretations of the images are provided under each micrograph. The scale bar represents $100 \mathrm{~nm}$. (E) The association of p2D10 with the genes is RNA-dependent. Salivary glands were permeabilized and digested with RNase A before immunofluorescent staining with $\mathrm{mAb} 1 \mathrm{~F} 2$ against $\mathrm{p} 2 \mathrm{D} 10$. The figure shows confocal sections through the nuclei of salivary gland cells treated with (right panel) and without (control, left panel) RNase A. (CYT) Cytoplasm; (NUC) nucleus. The magnification bar represents $25 \mu \mathrm{m}$.

(data not shown). This supports the conclusion that the detected activity corresponds to p2D10, as p2D10 coimmunoprecipitates with hrp65 (Fig. 4).

We also analyzed recombinant p2D10 using an in-gel activity assay in order to confirm that p2D10 has HAT activity. Recombinant p2D10 was expressed in Escherichia coli, the bacterial lysates were electrophoresed in histone-containing SDS-PAGE gels, and the gels were assayed for HAT activity. Figure 3B shows HAT-positive bands corresponding to full-length p2D10 ( 200 kDa) and proteolytic fragments of $\sim 80 \mathrm{kDa}$ and $120 \mathrm{kDa}$. p2D10 is an unstable protein, and it is commonly observed as two proteolytic fragments in the observed size range during gel electrophoresis (Sabri et al. 2002). Figure $3 \mathrm{~B}$ also shows the result obtained using negative control

A

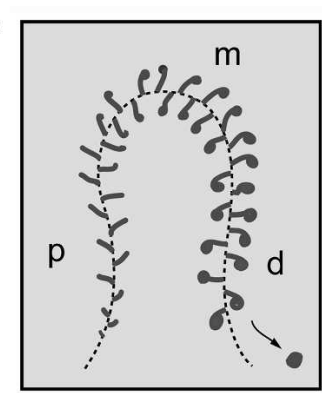

B

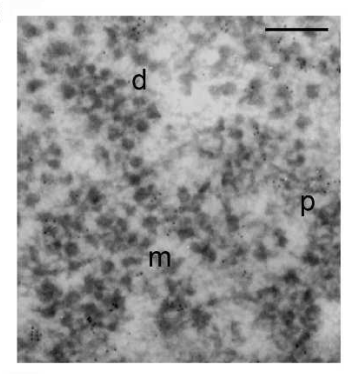

C
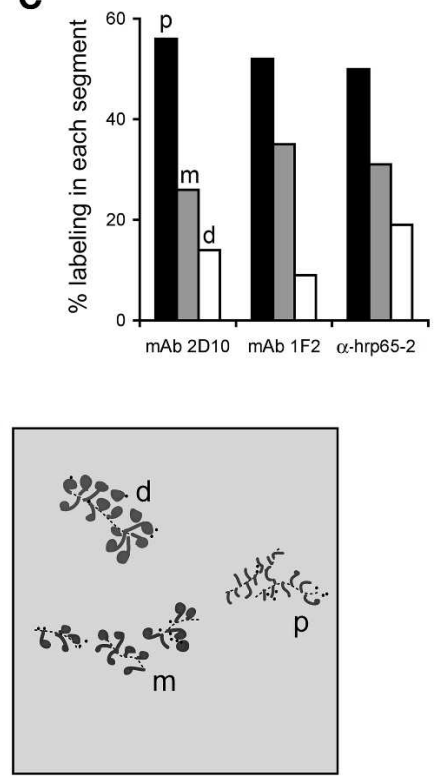

D
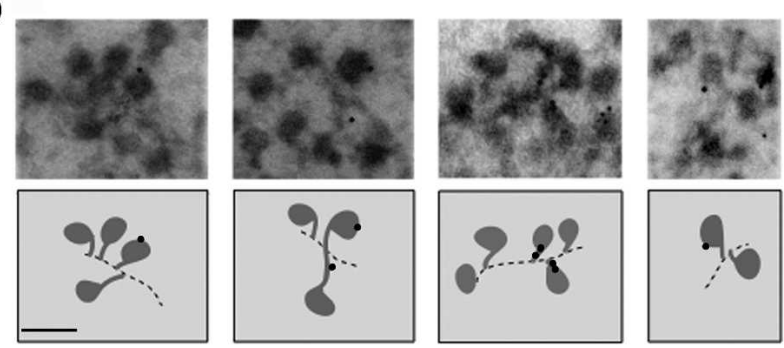

E

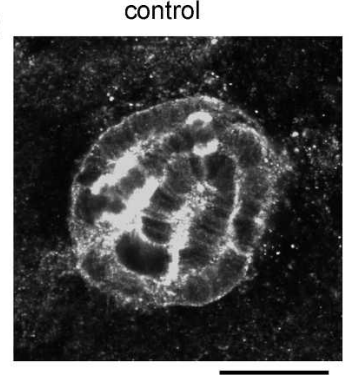

+ RNase A

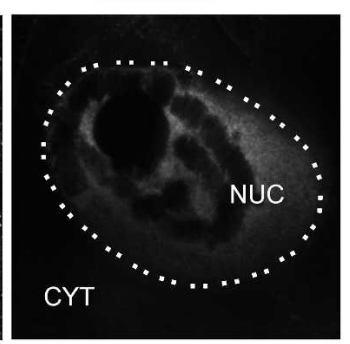


A

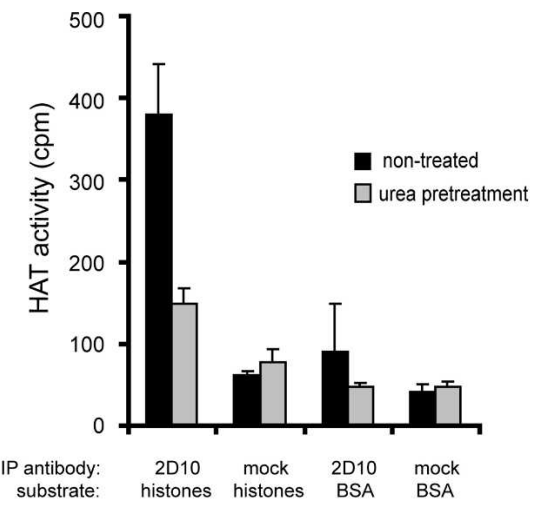

B

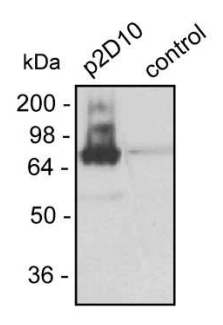

C

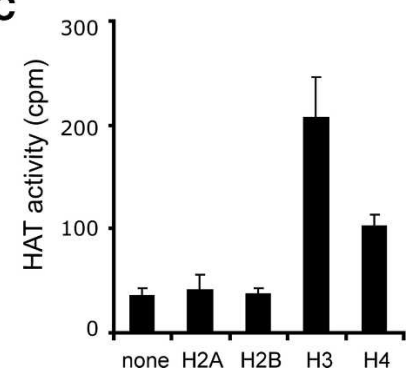

Figure 3. The histone acetyltransferase activity of p2D10. (A) p2D10 was immunoprecipitated from nuclear extracts and HAT activity was determined in solution using a mixture of core histones as substrate. Immunoprecipitations were performed according to standard protocols under native conditions (black bars) or using urea-treated extracts to dissociate protein complexes (gray bars). Control experiments were performed without specific antibody (mock) or with an alternative substrate, BSA, as indicated. $(B)$ Lysates of bacteria expressing recombinant p2D10 or empty vector (control) were subjected to in-gel HAT assays. $(C)$ Histone specificity was determined by immunoprecipitating p2D10 and determining HAT activity in solution using individual histones as substrate.

bacteria transformed with a vector that did not contain the insert.

We subsequently carried out HAT assays in solution using individual histones as substrates, in order to investigate the substrate specificity of p2D10. p2D10 acetylated histone $\mathrm{H} 3$ in vitro to a much higher extent than it acetylated the other histones (Fig. 3C). p2D10 acetylated $\mathrm{H} 4$ to some extent, while it did not acetylate $\mathrm{H} 2 \mathrm{a}$ and $\mathrm{H} 2 \mathrm{~b}$ at all.

\section{p2D10 binds directly to hrp65 and indirectly to actin}

Sabri et al. (2002) have shown that p2D10 can be coimmunoprecipitated with the mRNP-associated protein hrp65. We have carried out immunoprecipitation experiments after cross-linking proteins in vivo, in order to determine whether hrp65 and p2D10 interact directly. $C$. tentans tissue culture cells were treated with dithiobissuccinimidylpropionate (DSP), a cell-permeable, reversible, short-range $(\sim 11 \AA)$ cross-linker that reacts with primary amino groups (Wang and Richards 1974). After cross-linking the proteins, nuclear extracts were prepared and denatured by adding $8 \mathrm{M}$ urea, which disrupted all protein-protein interactions except the cross-linked ones. The denatured extracts were then used as input for immunoprecipitation using an $\mathrm{mAb}$ against hrp65. The immunoprecipitated proteins were studied by Western blotting using polyclonal antibodies against either hrp65 or p2D10. p2D10 coimmunoprecipitated from DSPtreated extracts under denaturing conditions (Fig. 4A). We conclude that p2D10 is directly cross-linked to hrp65, and that p2D10 and hrp65 interact directly in vivo.

hrp65 binds directly to actin in vivo (Percipalle et al. 2003), and this led us to examine the interaction be-
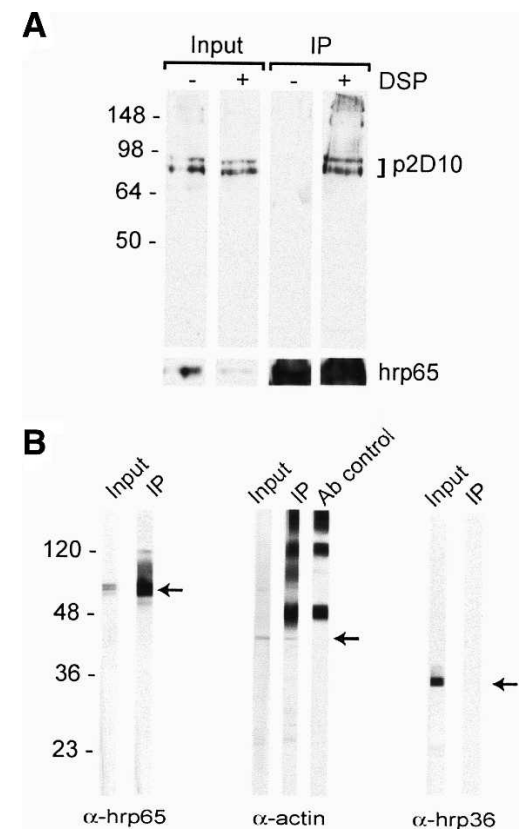

Figure 4. Interaction of p2D10 with actin and hrp65 in vivo. (A) p2D10 binds directly to hrp65. C. tentans tissue culture cells were treated with DSP in vivo, and nuclear extracts were prepared. Extracts were treated with urea to dissociate non-crosslinked proteins and subjected to immunoprecipitation using $\mathrm{mAb}$ 4E9 against hrp65. The immunoprecipitated material (IP) and the starting material (Input) were analyzed by Western blotting with anti-p2D10 antibodies. DSP cross-linking was reversed by the reducing SDS-PAGE sample buffer. $(B)$ Actin and hrp65 are coimmunoprecipitated by anti-p2D10 antibodies. p2D10 was immunoprecipitated from nuclear extracts prepared from C. tentans tissue culture cells using a peptide-specific antibody directed against p2D10. The starting material (Input) and precipitated material (IP) were analyzed by Western blotting with the indicated antibodies. The coimmunoprecipitated proteins are indicated by arrows. hrp36, an hnRNP protein abundant in the Input but not detected in the IP fraction, was assayed in parallel as a negative control to assess the specificity of the immunoprecipitation. In the detection of actin, the anti-rabbit antibodies used in the second step of the Western blot reacted against the primary anti-p2D10 antibody used in the immunoprecipitation, which results in several intense bands, as shown by a control immunoprecipitation carried out with the same antibodies without protein extract. 
tween actin and p2D10. We immunoprecipitated p2D10 from $C$. tentans nuclear extracts using $\mathrm{mAb} 2 \mathrm{D} 10$, and the coimmunoprecipitated proteins were analyzed by Western blotting. Both hrp65 and actin were specifically coimmunoprecipitated by the anti-p2D10 antibody (Fig. 4B). Hrp65 was more enriched than actin in the immunoprecipitates, which probably reflects the fact that hrp65 binds directly to p2D10, as shown above. hrp36, an abundant hnRNP protein of C. tentans, on the other hand, was not coimmunoprecipitated, and we conclude that the interaction between actin and p2D10 is specific.

Immunoprecipitation experiments after in vivo crosslinking revealed that there is no direct interaction between p2D10 and actin (data not shown).

In summary, p2D10 is associated with actin in vivo and the p2D10-actin interaction is mediated by hrp65.

\section{p2D10 is released from the chromosomes when} the 65-2CTS peptide is added

A synthetic peptide corresponding to the C-terminal sequence of the hrp65-2 isoform, referred to as "peptide 65-2CTS," can bind actin directly. This disrupts the interaction between actin and hrp65-2, and it inhibits Pol II transcription in living cells (Percipalle et al. 2003). Actin and hrp65 coimmunoprecipitated with p2D10 (Fig. $4 \mathrm{~B})$, and we have shown that p2D10 can acetylate histones (Fig. 3). This suggests that p2D10 is implicated in the inhibitory effect of the 65-2CTS peptide. Immunofluorescent staining of polytene chromosomes in the salivary glands of $C$. tentans larvae allowed us to determine whether the 65-2CTS peptide affects the association of p2D10 with transcribed genes. The salivary glands were dissected and incubated in culture medium with or without 65-2CTS peptide or control peptide (652mut1). The glands were fixed and immunostained with anti-p2D10 antibodies after incubation for $30 \mathrm{~min}$ (Fig. $5 \mathrm{~A})$. In control glands incubated in culture medium without any peptide, p2D10 was abundant in the nucleoplasm, and it was associated with many loci in the polytene chromosomes, including the BR genes (Fig. 5A). Treatment of the cells with the 65-2CTS peptide disrupted the association of p2D10 with the chromosomes and caused a drastic reduction of nuclear immunostaining. The number of cells per gland in which p2D10 was associated with the polytene chromosomes was recorded for each treatment in order to obtain a quantitative assessment of the effects of the peptide treatment. This revealed that the number of cells in which chromosomal staining could be detected was three times lower in 652CTS-treated glands than in untreated cells (see histogram in Fig. 5A). A control peptide, 65-2mut1, identical to 65-2CTS except for two point mutations that abolish actin binding (Percipalle et al. 2003), did not have any effect on the p2D10 distribution. The distribution of hrp45, an abundant RNA-binding protein of C. tentans (Alzhanova-Ericsson et al. 1996), was not changed in 652CTS-treated cells, which supports the specificity of the peptide treatment (Fig. 5B). We conclude that p2D10 is released from the chromosomes when the actin-hrp65 interaction is disrupted by the 65-2CTS peptide. This supports the hypothesis that p2D10 mediates the effect of the 65-2CTS peptide on transcription.

The 65-2CTS peptide reduces the acetylation level of histone $\mathrm{H3}$ in vivo

We immunostained glands treated with 65-2CTS and control glands with antibodies against the acetylated forms of histones $\mathrm{H} 3$ and $\mathrm{H} 4$ in order to determine whether the 65-2CTS peptide affects histone acetylation in vivo. The level of H3 acetylation was lower in glands treated with the 65-2CTS peptide than it was in control glands (Fig. 5C). In contrast, 65-2CTS did not affect the level of acetylation of histone H4 (Fig. 5D). Interestingly, histone $\mathrm{H} 3$ is the preferred substrate for $\mathrm{p} 2 \mathrm{D} 10$ in vitro (Fig. 3C).

The results suggested that the HAT activity of p2D10 is required to maintain the normal transcriptional activity of class II genes, and that the 65-2CTS peptide inhibits transcription due to release of p2D10 from the transcribed genes, following disruption of the actin-hrp65 complex. If this is so, HDACs in the nucleoplasm may deacetylate chromatin, eventually leading to the silencing of transcription. Furthermore, inhibition of HDAC activity would alleviate the inhibition that 65-2CTS causes in vivo. We tested this hypothesis in experiments using trichostatin A (TSA), a known inhibitor of HDAC activity, in combination with the 65-2CTS peptide. Salivary glands were incubated with 65-2CTS peptide and/or TSA for $30 \mathrm{~min}$, and transcription was monitored by BrUTP incorporation (Fig. 5E). Percipalle et al. (2003) have shown that administration of the 65-2CTS peptide alone causes a drastic reduction of BrUTP incorporation, and this occurred also in our experiments (Fig. 5E, second panel). In contrast, administration of 65-2CTS and TSA together (Fig. 5E,third panel), or TSA alone (Fig. 5E,fourth panel), did not affect BrUTP incorporation. We conclude that TSA can counteract the inhibitory effect of 65-2CTS, and this conclusion supports the hypothesis that the transcription inhibition caused by $65-2 \mathrm{CTS}$ is due to acetylation defects.

In summary, the HAT activity of p2D10 is required to maintain the normal transcriptional activity of the cell via $\mathrm{H} 3$ acetylation. The treatment with $65-2 \mathrm{CTS}$ peptide results in the release of $\mathrm{p} 2 \mathrm{D} 10$ from the transcribed genes, a subsequent decrease of $\mathrm{H} 3$ acetylation, and thus a reduction in transcription.

\section{Antibodies against p2D10 reduce transcription elongation}

p2D10 is associated with the growing BR pre-mRNP along the entire BR transcription unit, and it is therefore plausible that p2D10 plays a role in transcription elongation. In vitro transcription run-on assays in the presence or absence of antibodies against p2D10 allowed us to test this. Transcription run-on assays measure poly- 
Figure 5. Effects of the 65-2CTS peptide on p2D10 location, histone acetylation, and transcription. Each picture shows a confocal section through the nucleus of a salivary gland cell immunostained as indicated. $(A)$ Salivary glands dissected from fourth instar larvae were incubated for $30 \mathrm{~min}$ in culture medium with or without (Control) peptides, as indicated, and subsequently immunostained with $\mathrm{mAb} 1 \mathrm{~F} 2$ against p2D10. The number of nuclei per gland showing intense chromosomal staining was recorded, and the results of the quantification are summarized in the histogram. Four glands from two independent experiments were analyzed in each case. Treatment of the glands with 65-2CTS peptide caused a specific reduction in the association of p2D10 with the chromosomes. $(\mathrm{Nu})$ Nucleolus. $(B)$ Control and treated glands were processed as above and immunostained with mAb 2E4 against hrp45. The association of hrp45 with the chromosomes is not affected by treatment with the 652CTS peptide. Eight glands from two independent experiments were analyzed in each case. $(C, D)$ Control and treated glands were processed as above and stained with rabbit antibodies against either acetylated histone $\mathrm{H} 3(C)$ or acetylated histone $\mathrm{H} 4(D)$. The histograms show the percentage of nuclei per gland with intense nuclear staining. Twelve independent glands were analyzed in each case. Note that treatment of the glands with the 65-2CTS peptide resulted in specific reduction of histone $\mathrm{H} 3$ acetylation in vivo. $(E)$ Salivary glands were dissected and incubated for $30 \mathrm{~min}$ with or without 65-2CTS peptide and/or trichostatin A (TSA) as indicated, and the tran-

A

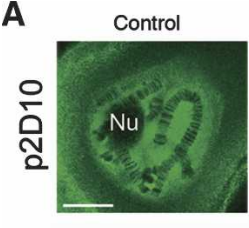

B

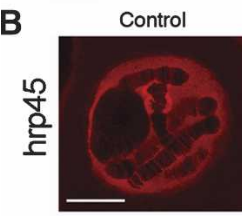

C

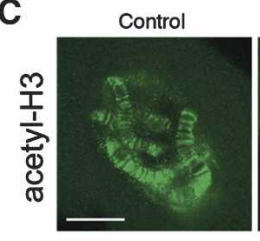

D
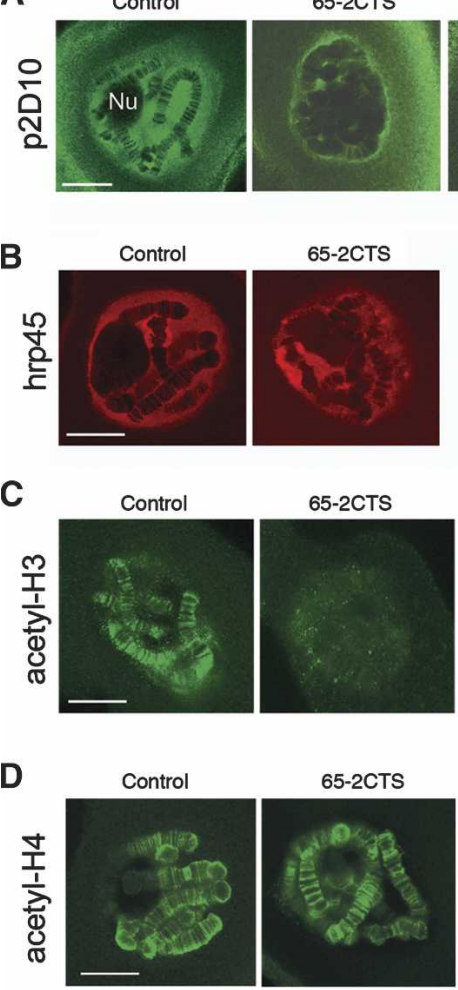

$65-2 \mathrm{CTS}$

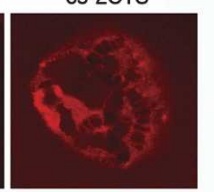

65-2CTS
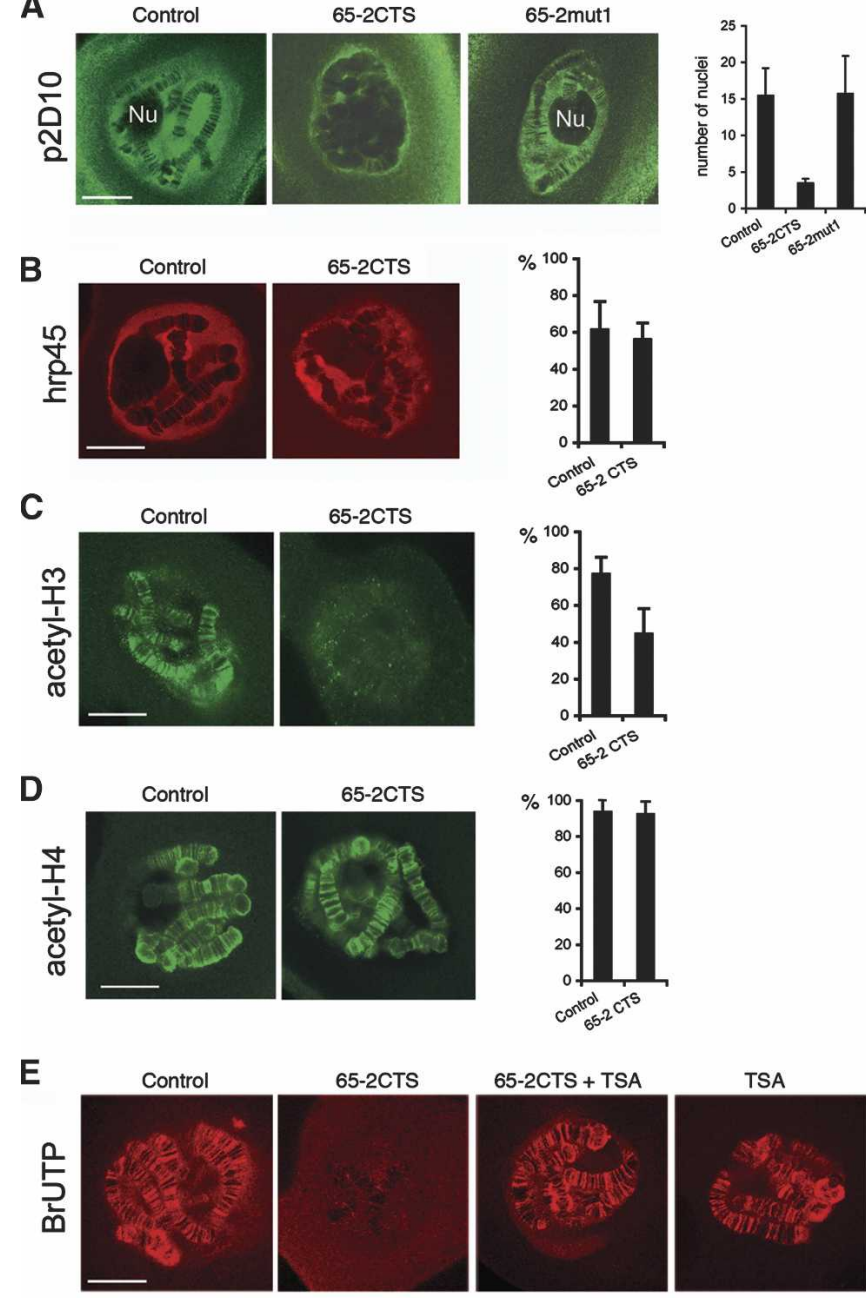

$65-2 \mathrm{CTS}$
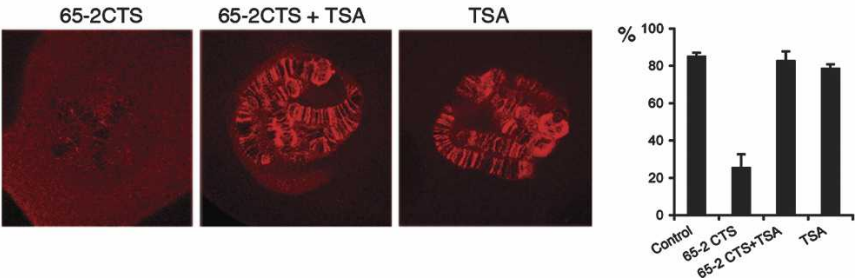

scriptional activity of the glands was sub-sequently assayed by BrUTP incorporation. The histogram shows the percentage of nuclei per gland with intense BrUTP staining. The number of glands analyzed in each case was $n=9,8,9$, and 4 for control, 65-2CTS, 65-2CTS + TSA, and TSA, respectively. In all cases, error bars indicate standard deviations, and magnification bars represent $25 \mu \mathrm{m}$. Results from two independent experiments were pooled.

merase density, do not support reinitiation events, and reflect the ongoing transcriptional activity on native chromatin templates in vivo. Nuclei from C. tentans cells were isolated, gently permeabilized, and submitted to run-on analysis in the presence of radiolabeled RNA precursors (Fig. 6A). p2D10-specific antibodies, either $\mathrm{mAb} 1 \mathrm{~F} 2$ or $\mathrm{mAb} 2 \mathrm{D} 10$, reduced RNA synthesis in the run-on reaction to a level significantly lower than that in control reactions with antibodies against unrelated proteins, either mAb 6C10 (Fig. 6B,C) or mAb 2B4 (data not shown). The run-on reactions were carried out in conditions that inhibit transcription initiation but support elongation (Hawley and Roeder 1985), that is, in the presence of $0.015 \%$ sarkosyl (Fig. 6B, lanes $1-4)$. No run-on products were detected in the presence of $0.08 \%$ sarkosyl, a concentration that is known to inhibit elongation (Fig. 6B, lane 5). The run-on elongation was also inhibited by $3 \mu \mathrm{g} / \mathrm{mL} \alpha$-amanitin (Fig. 6B, lane 4), which in- dicates that the transcription products were synthesized by Pol II. We conclude that p2D10 is involved in transcription in vivo and, in particular, that it is involved in transcription elongation by Pol II.

\section{hrp65 and p2D10, but not actin, are released from the transcribed genes when the actin-hrp65 complex is disrupted}

p2D10 binds to hrp65 directly and to actin indirectly (Fig. 4), and p2D10 is released from the chromosomes when the actin-hrp65 complex is disrupted by the 652CTS peptide (Fig. 5A). We analyzed the effect of the 65-2CTS peptide on the association of actin and hrp65 with active genes, to try to establish the order in which actin, hrp65, and p2D10 are recruited to the growing premRNA. Salivary glands were treated with or without the 65-2CTS peptide, and the association of actin and 

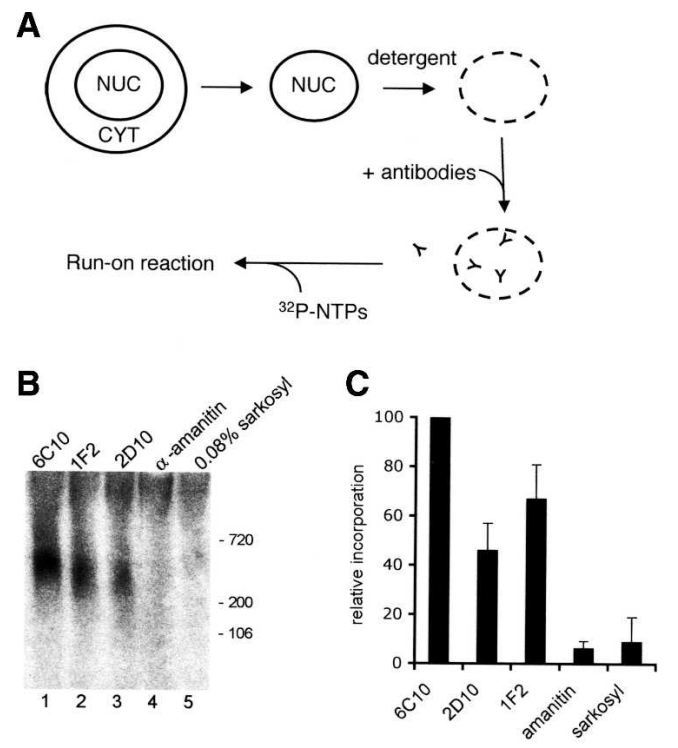

Figure 6. Specific inhibition of run-on transcription by antip2D10 antibodies. (A) Schematic depiction of the run-on assay to test global effects of specific antibodies on transcription elongation. $(B)$ Permeabilized nuclei were prepared from cultured $C$. tentans cells, incubated with or without antibodies as indicated, and subjected to transcription run-on analysis. mAbs 1F2 (lane 2) and 2D10 (lane 3) are against p2D10, and mAb 6C10 (lane 1) is against an unrelated chromosomal protein of $35 \mathrm{kDa}$. In lane 4, the run-on reaction was performed in the presence of $3 \mu \mathrm{g} / \mathrm{mL} \alpha$-amanitin. The run-on reactions in lanes $1-4$ were performed in the presence of $0.015 \%$ sarkosyl, whereas the reaction in lane 5 is a negative control with $0.08 \%$ sarkosyl. The RNA elongated in the run-on was resolved in urea-polyacrylamide gels, and the levels of ribonucleotide incorporation into RNA were measured by phosphorimaging in the 200-700-nt range. $(C)$ The histogram shows the relative levels of ribonucleotide incorporation into RNA determined by PhosphorImager analysis. Values indicate mean \pm standard deviation of three independent experiments.

hrp65-2 with transcribed genes was analyzed by immunofluorescence (Fig. 7). The anti-actin and anti-hrp65-2 antibodies stained the chromosomes poorly, and the variability within one salivary gland was often high. This made it difficult to quantify the results by direct scoring. We devised, therefore, a more sensitive, computer-based approach to measuring changes in the intensity of the immunostaining. Treated and control glands were double-stained with either anti-actin or antihrp65-2 antibodies, and a mAb against hrp45, an RNAbinding protein (Alzhanova-Ericsson et al. 1996), that was used here as a marker to identify the BR puffs in the preparations. Control experiments showed that the average intensity of hrp45 staining on BR puffs was not affected by 30 -min treatment with the 65-2CTS peptide (Fig. 5B). This made hrp45 a suitable reference for quantitative purposes. Double-stained glands were examined in the confocal microscope, and nuclei with satisfactory hrp45 staining were recorded. The area of the BRs was then selected as illustrated in Figure 7B, and the mean intensities of fluorescence, both from anti-hrp45 and from anti-actin and anti-hrp65-2, in the selected areas were determined. Finally, the average intensity of fluorescence of either anti-actin or anti-hrp65-2 staining in the selected areas was calculated relative to that of antihrp45 staining, in order to compensate for variations in the activity of the BR puffs. Treatment of the glands with the 65-2CTS peptide reduced the relative intensity of the anti-hrp65-2 immunostaining (Fig. 7C), which suggests that hrp65-2 is released from the chromosomes when the actin-hrp65-2 complex is disrupted. The intensity of the anti-actin staining, in contrast, increased, showing that actin remains associated with the chromosomal loci after 65-2CTS treatment. The increased signal may be due to a higher accessibility for the antibody after the complex has been disrupted and both hrp65-2 (Fig. 7A,C) and p2D10 (Fig. 5A) have been released from the chromosomes. In summary, we suggest that actin is more closely bound to the growing pre-mRNA than hrp65-2 and p2D10 are bound (Fig. 8).
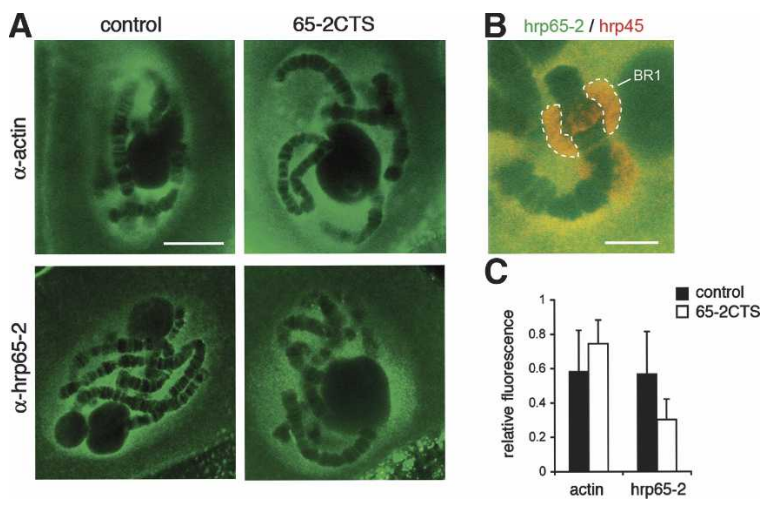

Figure 7. The association of hrp65-2 with the genes is disrupted by the 65-2CTS peptide. Each picture shows a confocal section through the nucleus of a salivary gland cell immunostained as indicated. (A) Salivary glands dissected from fourth instar larvae were incubated for $30 \mathrm{~min}$ in culture medium with or without (control) peptides, as indicated, and subsequently immunostained with antibodies against either actin or hrp65-2. In control glands, both proteins showed intense nucleoplasmic accumulation, and positively stained bands in the chromosomes. Treatment of the glands with the 65-2CTS peptide did not change the location of actin but reduced the levels of chromosomal hrp65-2. (B) Salivary glands treated as above were double-stained with $\mathrm{mAb}$ anti-hrp45, used as a marker for BR puffs, and either anti-actin or anti-hrp65-2 antibodies. The micrograph shows a control chromosome stained for hrp65-2 (green) and hrp45 (red). Possible changes in the association of actin and hrp65-2 with transcriptionally active loci were analyzed by selecting BR puffs on the basis of the hrp45 staining (red), and measuring the intensity of labeling in the BR puffs relative to hrp45, as described in the Results. $(C)$ The results of the quantitative analysis. The histogram shows the levels of fluorescence for actin and hrp65-2, relative to hrp45, in BR puffs from control and treated glands, as indicated. Values indicate mean \pm standard deviation. $n=16$ and 19 for actin control and treated, respectively, and $n=20$ and 25 for hrp65-2 control and treated, respectively. Results from two independent experiments were pooled. The scale bars represent $\sim 20 \mu \mathrm{m}$ in $A$ and 10 $\mu \mathrm{m}$ in $B$. 


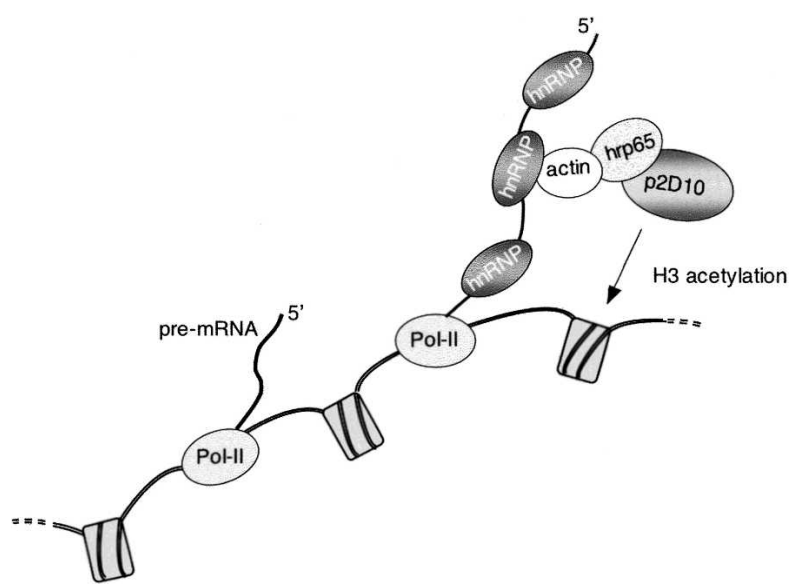

Figure 8. A model for the cotranscriptional recruitment of p2D10 to the growing pre-mRNP. Actin, hrp65, and p2D10 become incorporated into the growing pre-mRNP cotranscriptionally. This serves to localize p2D10 close to its substrate, histone $\mathrm{H} 3$. We do not know whether p2D10 can reach and acetylate H3 while bound to the pre-mRNP, or whether the HAT activity of p2D10 is dependent on high on-off rates. The proposed order of assembly of the proteins on the pre-mRNA is based on reported protein-protein interactions and on the effect of the 65-2CTS peptide on the association of actin, hrp65, and p2D10 with the chromosomes. Although binding of the actin-hrp65-p2D10 complex to the growing RNA could be mediated by the RNAbinding domains of hrp65, we favor the hypothesis that actin mediates such association by binding to hnRNP proteins.

\section{Discussion}

The mRNP-associated protein hrp65 binds directly to actin. Disruption of the actin-hrp65 interaction in vivo by the competing peptide 65-2CTS causes a drastic reduction of transcription (Percipalle et al. 2003). We have shown that the inhibitory effect of the 65-2CTS peptide on transcription is counteracted by TSA, a drug that inhibits HDACs. We have also shown that actin and hrp65 are associated in vivo with p2D10, an evolutionarily conserved protein in $C$. tentans with HAT activity that acts preferentially on histone $\mathrm{H} 3$. We have shown that the p2D10 protein is associated with transcribed genes, and we have shown by immuno-EM, using the BR genes of $C$. tentans as a model system, that p2D10 is associated with the growing pre-mRNA during transcription. We have also shown that p2D10 is released from the chromosomes when the actin-hrp65 interaction is disrupted by the 65-2CTS peptide, and that at the same time the levels of histone $\mathrm{H} 3$ acetylation in vivo decrease, and that transcription is inhibited. Furthermore, antibodies against p2D10 inhibit run-on transcription. In summary, these results suggest that the actin-hrp65 complex recruits p2D10 to the transcribing genes, where the HAT activity of p2D10 contributes to maintaining acetylated histone H3 (Fig. 8). The growing pre-mRNP may, surprisingly, play a role in tethering chromatin-modifying factors that contribute to maintaining the gene in its active state.
p2D10, a Pol III factor associated with class II genes

TFIIIC, or $\tau$ in Saccharomyces cerevisiae, is a large multi-subunit factor required for the transcription of class III genes. TFIIIC is responsible for promoter recognition and for TFIIIB assembly. Some of the TFIIIC subunits are evolutionarily conserved among eukaryotes. The largest subunit of TFIIIC, named TFIIIC220 in human and $\tau 138 / \mathrm{Tfc} 3$ in S. cerevisiae, is a DNA-binding protein that can recognize and bind directly to several cis-elements in class III promoters (for review, see Schramm and Hernandez 2002).

We have studied the p2D10 protein, which is similar in sequence to human TFIIIC220 and yeast $\tau 138 / \mathrm{Tfc} 3$ (Sabri et al. 2002). It has not been shown that p2D10 plays a role in the transcription of Pol III genes, but comparing the cDNA sequences strongly suggests that p2D10 is the C. tentans ortholog of human TFIIIC220. Only one gene with significant homology to human TFIIIC220 has been found in the genomes of Drosophila melanogaster (Q9VJY7) and Anopheles gambiae (Q7QCJ4). TFIIIC220 is also a unique gene in the human, mouse, and rat genomes. This suggests that no additional TFIIIC220-related genes exist in C. tentans, and that p2D10 is the TFIIIC220 ortholog in C. tentans.

Sabri et al. (2002) have identified two types of p2D10containing complexes that differ in molecular mass and composition, using gel filtration chromatography and coimmunoprecipitation methods. One of these complexes, the heavier, contains at least one other component of the TFIIIC complex, TFIIIC- $\varepsilon$, and may correspond to the Pol III holoenzyme. The other complex contains RNA and other proteins, such as hrp65, involved in mRNA biogenesis. Sabri et al. (2002) proposed, supported by the existence of the light complex, that p2D10 has a dual function, and that it is involved not only in the initiation of transcription of class III genes but also in pre-mRNA biogenesis. p2D10 is located at genes transcribed by Pol II, supporting Sabri's proposal. Interestingly, a genomewide study of the distribution of the Pol III machinery in the genome of $S$. cerevisiae revealed that TFIIIC is associated with intergenic regions located close to several protein-coding genes, in addition to the expected location at class III genes (Moqtaderi and Struhl 2004). This suggests that the function of TFIIIC in expression of class II genes is evolutionarily conserved.

We have not directly analyzed whether p2D10 plays a role in transcription of ribosomal genes. However, the immunostaining of salivary glands with anti-p2D10 antibodies did not show any association of p2D10 with nucleoli (Figs. 1, 5A), which argues against the involvement of p2D10 in transcription by Pol I.

Actin and hrp65: a platform for recruiting chromatin modifiers

Our results suggest that hrp65 mediates the recruitment of p2D10 to the BR genes. Firstly, cross-linking experiments show that p2D10 and hrp65 interact directly in vivo (Fig. 4A). Secondly, the distribution of p2D10 along 
the BR transcription unit parallels that of hrp65-2 (Fig. 2C; Percipalle et al. 2003). Thirdly, p2D10 is released from the transcription sites (Fig. 5A) when the 65-2CTS peptide is added. This peptide disrupts actin-hrp65-2 interaction in vivo (Percipalle et al. 2003) and results in release of hrp65 from the chromosome (Fig. 7). Fourthly, immuno-EM shows that at least a fraction of p2D10 is associated with the growing pre-mRNP, not with the chromatin (Fig. 2D). In summary, the recruitment of p2D10 to the transcriptionally active genes occurs at the RNP level and is probably mediated by hrp65. Thus, the targeting of p2D10 to class II or class III genes is achieved by two different mechanisms: direct DNA binding to Pol III promoters, and indirect recruitment to Pol II genes by binding to the growing pre-mRNP via protein-protein interactions.

Antibodies against p2D10 coimmunoprecipitate both hrp65 and actin (Fig. 4B). This has led us to propose that a complex containing p2D10, actin, and hrp65 exists. Further evidence for this complex comes from the finding that actin and hrp65-2 interact directly (Percipalle et al. 2003), as do p2D10 and hrp65 (Fig. 4A). The interactions between the different hrp65 isoforms (Kiesler et al. 2003) make it difficult to discern the role of each isoform. We believe that such a p2D10-hrp65-actin complex probably contains both hrp65-2 and hrp65-1.

The association of the p2D10-hrp65-actin complex with the growing pre-mRNA may be mediated by the RNA-binding domains of hrp65. However, direct binding of hrp65 to mRNA has not been demonstrated, and according to our results, actin is more closely bound to the growing pre-mRNA than hrp65 and p2D10 (Fig. 7). Although we cannot exclude the possibility that hrp65 binds directly to the pre-mRNA, we suggest that actin binds to the growing pre-mRNP via direct contacts with hnRNP proteins, such as C. tentans hrp36. Previous reports on the binding of actin to hnRNP proteins in both insects and mammals support this suggestion (Percipalle et al. 2001, 2002; Kukalev et al. 2005).

Actin is associated with the BAF chromatin-remodeling complexes (Zhao et al. 1998), and a large number of actin-related proteins are components of chromatin-remodeling complexes implicated in the regulation of transcription (for review, see Pederson and Aebi 2003; Olave et al. 2002). Recently, however, in vitro transcription assays on naked DNA templates have led to the proposal that actin plays a role that is independent of chromatin. Hofmann et al. (2004) showed that actin acts at early stages of Pol II transcription as part of the preinitiation complex. Philimonenko et al. (2004) have shown that it acts in Pol I transcription at a post-initiation step. Hu et al. (2004) have shown that actin is associated with Pol III and is essential for Pol III transcription. These observations suggest that actin is involved in several steps of the transcription process. Interestingly, research on nuclear actin has revealed that actin associates with several mRNA-binding proteins both in insects (Percipalle et al. 2001, 2003) and in mammals (Percipalle et al. 2002; Zhang et al. 2002; Kukalev et al. 2005), while our present results suggest that actin associated with mRNA-bind- ing proteins is involved in recruiting chromatin-modifying factors to actively transcribing genes. The suggestion that actin is involved in recruiting chromatin modifiers does not conflict with the proposal that actin plays an additional, earlier role that is independent of chromatin. It is also possible that actin is recruited to the promoter as part of the preinitiation complex, and subsequently transferred to the growing pre-mRNA, as has been proposed for other factors involved in pre-mRNA biogenesis.

In summary, we suggest that actin, hrp65, and p2D10 are parts of a positive feedback mechanism that contributes to maintaining the active transcription state of a gene by recruiting HATs at the RNA level. The 65-2CTS peptide inhibits transcription, while actin can adopt different conformational states, and these facts raise the possibility that the p2D10-hrp65-actin complex acts as a "transcription switch" that can shut off transcription by releasing the HATs when a gene needs to be silenced. Changes in the actin conformation are well documented and may mediate the transition from the active state to the silent state of a gene.

We consider unlikely that the HAT activity of p2D10 alone accounts for the dramatic transcriptional shut-off observed in our experiments. Interestingly, acetylated $\mathrm{H} 3$ and $\mathrm{H} 4$ play a crucial role in recruiting chromatinremodeling factors that contain bromodomains (Ladurner et al. 2003; Matangkasombut and Buratowski 2003), and these remodeling factors may have more dramatic effects on gene expression than $\mathrm{H} 3$ acetylation alone. Moreover, the cotranscriptional association of actin with growing pre-mRNPs and the subsequent recruiting of chromatin modifiers that we report here may take place in other systems. A recent study has shown that actin binds to hnRNP U in human cells (Kukalev et al. 2005) and another study has shown, interestingly, that hnRNP $U$ is coupled to HAT activity (Martens et al. 2002). Thus, the actin-hnRNP U complex has many features in common with the hrp65-actin complex, and both appear to be involved in recruiting chromatin modifiers to active genes.

\section{The role of the $R N P$ in chromatin remodeling during transcription elongation}

Studies of the modification and remodeling of chromatin that take place when genes are expressed have mainly focused on the initiation of transcription. However, during the last years it has become evident that transcription elongation also requires the structure of chromatin to be modified (for review, see Hartzog et al. 2002; Sims et al. 2004; Svejstrup 2004). Several mechanisms by which chromatin-remodeling factors are recruited to the transcribed chromatin can be envisioned. The transcription machinery itself may bind and transport regulatory factors along the complete transcription unit, and indeed the C-terminal domain (CTD) of the largest subunit of Pol II plays a role in regulating elongation through chromatin (for review, see Hartzog et al. 2002). Our results suggest that there is an alternative mechanism by which 
chromatin regulators are targeted to transcribed genes: by chromatin regulators binding to growing transcripts.

Several examples of RNA-binding proteins or RNAprocessing factors that influence transcription have been reported in recent years (for review, see Manley 2002; Zorio and Bentley 2004). The spliceosomal U small nuclear ribonucleoproteins (snRNPs) interact with the human transcription elongation factor TAT-SF1 and regulate polymerase elongation, probably by the binding of TAT-SF1 to the elongation factor P-TEFb (Fong and Zhou 2001). The transcription elongation regulator 1 , CA150, binds to the phosphorylated CTD of elongating Pol II and to TAT-SF1, and it has been proposed that CA150 regulates the rate of transcriptional elongation such that it corresponds to the demands imposed by cotranscriptional splicing (Goldstrohm et al. 2001). A fraction of U1 snRNA is associated with TFIIH, and the interaction between these proteins results in a higher rate of transcription initiation (Kwek et al. 2002). The Elongator, a HAT complex that acts primarily on histone $\mathrm{H} 3$, associates with the growing RNA during transcription (Gilbert et al. 2004). Two enzymes involved in premRNA capping in yeast, Abdl and Cet1, regulate the function of Pol II at early stages of transcription to favor cotranscriptional capping (Myers et al. 2002; Schroeder et al. 2004). Transcription by Pol I also requires tUtps, a family of factors involved in pre-rRNA processing (Gallagher et al. 2004). The common theme in these examples, and in our results, is the existence of RNA-binding proteins or RNA-processing factors that influence transcription from the RNA. The cotranscriptional assembly of a correct ribonucleoprotein particle is crucial for post-transcriptional events such as mRNA surveillance and export (for review, see Neugebauer 2002; Jensen et al. 2003; Reed 2003). Our results suggest that cotranscriptional RNP assembly is also important for the tethering of chromatin-modifying factors that facilitate elongation through chromatin and that can contribute to maintaining the gene in an active state.

\section{Materials and methods}

\section{Culturing conditions}

Chironomus tentans was cultured as described by Meyer et al. (1983). Salivary glands were isolated from fourth instar larvae. When indicated, fourth instar larvae were cultivated in the presence of $0.5 \%$ galactose for 4-6 d. C. tentans tissue culture cells were cultivated at $22^{\circ} \mathrm{C}$ as previously described (Wyss 1982).

\section{Antibodies}

Two independent mAbs against p2D10, mAbs 2D10 and 1F2, and two peptide-specific antibodies have been characterized by Sabri et al. (2002). mAbs 2B4 and 6C10 against C. tentans nuclear proteins of 40 and $35 \mathrm{kDa}$, respectively, originate from the same fusions as the anti-p2D10 mAbs and were used as control antibodies in run-on experiments. The anti-actin antibody was a rabbit serum raised against Chironomus actin kindly provided by P. Percipalle (Karolinska Institute, Stockholm, Sweden). The mAb 4E9 against all the hrp65 isoforms has been characterized by Miralles et al. (2000). The peptide-specific rabbit antibody against hrp65-2 has been characterized by Percipalle et al. (2003). The antibodies against acetylated histones H3 and $\mathrm{H} 4$ are from UpState and the anti-Br-UTP antibody from Roche.

\section{Immunostaining of polytene chromosomes}

Salivary glands were fixed with $3.7 \%$ formaldehyde in $45 \%$ acetic acid in PBS for $\sim 10 \mathrm{~min}$, and subsequently squashed in a drop of $45 \%$ acetic acid. The slides were frozen on dry ice, the coverslips were pried off, and the preparations were further fixed with $3.7 \%$ formaldehyde in PBS for $15 \mathrm{~min}$. The slides were then washed in PBS, dehydrated, and stored in absolute ethanol at $-20^{\circ} \mathrm{C}$. Before immunostaining, the slides were rehydrated, washed with PBSG (PBS containing 0.1 M glycine) for $10 \mathrm{~min}$, and blocked with a solution of $5 \%$ non-fat powdered milk in PBSG. Samples were incubated with primary antibodies $(0.1-1$ $\mu \mathrm{g} / \mathrm{mL}$ for mAbs, or 1:1000 for rabbit sera) for $1 \mathrm{~h}$, and they were incubated with 6-nm gold-conjugated secondary antibody (Jackson ImmunoResearch Laboratories) for $40 \mathrm{~min}$. The labeling was silver-enhanced with IntenSE (Amersham Biosciences), and the specimens were examined and photographed in a light microscope (Zeiss).

\section{Preparation of nuclear extracts}

C. tentans tissue culture cells were homogenized in PBS (137 $\mathrm{mM} \mathrm{NaCl}, 3 \mathrm{mM} \mathrm{KCl}, 8 \mathrm{mM} \mathrm{Na}_{2} \mathrm{HPO}_{4}, 2 \mathrm{mM} \mathrm{NaH}_{2} \mathrm{PO}_{4}$ at $\mathrm{pH}$ 7.2) containing $0.2 \%$ Nonident P40 (NP-40), $100 \mu \mathrm{g} / \mathrm{mL}$ PMSF, $5 \mathrm{mM}$ benzamidine, $10 \mu \mathrm{g} / \mathrm{mL}$ aprotinin, $10 \mu \mathrm{g} / \mathrm{mL}$ leupeptin, and $10 \mu \mathrm{g} / \mathrm{mL}$ pepstatin using a glass homogenizer. The homogenate was centrifuged at $1500 \mathrm{~g}$ for $10 \mathrm{~min}$ at $4^{\circ} \mathrm{C}$. The supernatant was the cytoplasmic fraction. The pellet containing the nuclei was resuspended in PBS supplemented as above, sonicated three times for 4-5 sec each time, and centrifuged as above. The resulting supernatant was the soluble nuclear extract, and was used as input for the immunoprecipitations.

\section{Immunoprecipitation}

The mAb 2D10 was added to crude nuclear extract to give a final concentration of $\sim 10 \mu \mathrm{g} / \mathrm{mL}$ in the presence of $0.1 \%$ NP40. The extract was then incubated for $90 \mathrm{~min}$ at $4^{\circ} \mathrm{C}$ with gentle rotation. Anti-mouse IgM immunoglobulins (Zymed Laboratories) were added, and the rotation was continued for an additional $90 \mathrm{~min}$ at $4^{\circ} \mathrm{C}$. Finally, protein-G Sepharose beads (Zymed Laboratories) were added, and the rotation was continued overnight at $4^{\circ} \mathrm{C}$. The Sepharose beads were washed twice with PBS containing $0.1 \%$ NP-40 and once with PBS. The Sepharose beads from p2D10 immunoprecipitation were immediately used for acetyltransferase assays. For coimmunoprecipitation analysis of actin and hrp65, the p2D10 antibody pepII (Sabri et al. 2002) was used for precipitation, and mAb 4E9 and a polyclonal anti-actin antibody were used for detection.

\section{In vivo protein-protein cross-linking}

Proteins in C. tentans tissue culture cells were cross-linked for $20 \mathrm{~min}$ at room temperature with $0.05 \%(\mathrm{w} / \mathrm{v})$ dithiobis-succinimidylpropionate (DSP; Sigma-Aldrich) in serum-free cultivation medium. Nuclear extracts were prepared as described above and treated with $8 \mathrm{M}$ urea. The extracts were diluted 10 times with PBS and immediately used for immunoprecipitation as described above using a hrp65-specific antibody (mAb 4E9). The proteins were eluted after immunoprecipitation with $0.5 \%$ 
SDS at room temperature. The eluted proteins were precipitated with acetone and subsequently analyzed by Western blotting.

\section{Histone acetyltransferase (HAT) activity assay}

For in-gel HAT assays, E. coli strain BL21 was transformed with pET21 vector containing an insert encoding full-length p2D10. Bacterial extracts from induced cultures were dissolved in SDSPAGE sample buffer and separated by SDS-PAGE in 10\% polyacrylamide gels containing $0.1 \mathrm{mg} / \mathrm{mL}$ core histones. Control gels were prepared with bovine serum albumin (BSA) instead of histones (data not shown). The gel was washed after electrophoresis for $1 \mathrm{~h}$ at room temperature in buffer A $150 \mathrm{mM}$ Tris- $\mathrm{HCl}$ at $\mathrm{pH}$ 8.0, $1 \mathrm{mM}$ DTT, $0.1 \mathrm{mM}$ EDTA) containing $20 \%$ isopropanol, and then washed for $1 \mathrm{~h}$ in buffer A containing $8 \mathrm{M}$ urea. The gel was then incubated in buffer A containing 0.04\% Tween- 40 overnight at $4^{\circ} \mathrm{C}$. The gel was transferred to buffer B (buffer A containing 10\% glycerol and $1 \mathrm{mM} \mathrm{PMSF}$ ) and washed for $1 \mathrm{~h}$ at $30^{\circ} \mathrm{C}$. Acetylation was initiated by adding $20 \mu \mathrm{Ci}$ of ${ }^{3} \mathrm{H}$-acetyl-CoA. After incubation for $30 \mathrm{~min}$ at $30^{\circ} \mathrm{C}$, the gel was washed in 5\% TCA for $30 \mathrm{~min}$, in water for $30 \mathrm{~min}$, in $5 \%$ acetic acid for $30 \mathrm{~min}$, and finally in water for $30 \mathrm{~min}$. Acetylated histones were detected by fluorography.

We carried out HAT assays in solution with native p2D10 isolated from C. tentans cells by immunoprecipitation as described above. Sepharose beads from p2D10 immunoprecipitations were resuspended in $30 \mu \mathrm{L}$ of assay buffer $(50 \mathrm{mM}$ Tris at $\mathrm{pH} 8.0,10 \%$ glycerol, $1 \mathrm{mM}$ DTT, $10 \mathrm{mM}$ butyrate). Then $4.5 \mu \mathrm{g}$ of histones and $25 \mathrm{nCi}$ of ${ }^{3} \mathrm{H}$-acetyl-CoA were added, and the mixture was incubated for $1 \mathrm{~h}$ at $30^{\circ} \mathrm{C}$. For substrate specificity determinations, $1.5 \mu \mathrm{g}$ of each recombinant histone (Upstate) was used as substrate. The reaction was spotted onto p81 phosphocellulose filters (Whatman) and allowed to adsorb for 20 min. The filters were soaked in $50 \mathrm{mM}$ sodium carbonate $(\mathrm{pH}$ 9.2) for $30 \mathrm{~min}$ and washed briefly in acetone. Membrane-bound radioactivity was determined by liquid scintillation.

\section{Immunofluorescence of $\mathrm{C}$. tentans salivary glands}

C. tentans salivary glands were isolated and immediately fixed with $3.7 \%$ formaldehyde in PBS for $15 \mathrm{~min}$ on ice. Following fixation, the glands were permeabilized for $11 \mathrm{~min}$ at room temperature with $0.2 \%$ SDS in PBS. The preparations were blocked with $3 \%$ BSA in PBS and subsequently incubated with the primary antibody overnight at $4^{\circ} \mathrm{C}$, and then incubated for $1 \mathrm{~h}$ at room temperature. The preparations were then washed, incubated with the secondary antibody for $1 \mathrm{~h}$ at room temperature, washed again, and finally mounted in Vectashield (Vector Laborarories). Preparations were analyzed and images were taken with an LSM 510 Laser Scanning Microscope (Zeiss). The optical sections were $\sim 1 \mu \mathrm{m}$ thick. For peptide and drug treatments, the glands were incubated in ZO-medium (Wyss 1982) containing either $0.25 \mathrm{mM}$ peptide 65-2CTS (Percipalle et al. 2003), or $0.25 \mathrm{mM}$ peptide $65-2 \mathrm{mut}$, and/or $0.1 \mu \mathrm{M}$ trichostatin A (Sigma-Aldrich) for $30 \mathrm{~min}$ at room temperature prior to fixation and immunostaining. For RNase A digestion, the glands were incubated in glycerol buffer and permeabilized in Triton X-100 as for BrUTP incorporation (see below), washed in PBS and incubated in $0.1 \mathrm{mg} / \mathrm{mL}$ DNase-free RNase A in TBS for $30 \mathrm{~min}$ at room temperature. After the RNase A digestion, the glands were fixed and processed for immunofluorescence as above. Control glands were treated in parallel with omission of RNase A.

\section{Analysis of transcriptional activity by BrUTP incorporation}

C. tentans salivary gland cells were dissected and incubated with or without peptides and/or TSA as above. The preparations were incubated in glycerol buffer $(20 \mathrm{mM}$ Tris- $\mathrm{HCl}$ at $\mathrm{pH} 7.4,5$ $\mathrm{mM} \mathrm{MgCl} 2,25 \%$ glycerol, $0.5 \mathrm{mM}$ EGTA, $0.5 \mathrm{mM}$ PMSF) for 3 $\mathrm{min}$ at room temperature, and then in glycerol buffer containing $0.05 \%$ Triton X-100 for $3 \mathrm{~min}$ at room temperature. After washing in transcription buffer $(100 \mathrm{mM} \mathrm{KCl}, 50 \mathrm{mM}$ Tris- $\mathrm{HCl}$ at $\mathrm{pH}$ 7.4, $5 \mathrm{mM} \mathrm{MgCl}_{2}$, 25\% glycerol, $0.5 \mathrm{mM}$ EGTA), the glands were incubated in transcription buffer supplemented with 0.5 mM each of ATP, CTP, and GTP (Amersham Biosciences) and $0.2 \mathrm{mM}$ of BrUTP (Sigma-Aldrich). The preparations were washed with $0.5 \%$ Triton X-100 in PBS and subsequently processed for immunofluorescence as described above, using an $\mathrm{mAb}$ against BrUTP (Roche) as primary antibody.

\section{Immuno-EM}

Salivary glands were fixed for $20-25 \mathrm{~min}$ in $4 \%$ paraformaldehyde and $0.1 \%$ glutaraldehyde, cryoprotected with sucrose, frozen, and cryosectioned. The cryosections, $70-80 \mathrm{~nm}$ thick, were picked up on drops of $2.3 \mathrm{M}$ sucrose and mounted onto nickel grids coated with formvar and carbon. The grids were floated onto drops of PBS containing $0.1 \mathrm{M}$ glycine and $10 \%$ fetal calf serum before incubation with the antibody solutions. The secondary antibody against rabbit IgM, conjugated to 6-nm gold particles (Jackson Immuno Research Laboratories), was diluted 1:50 in PBS containing 5\% fetal calf serum. After immunolabeling, the sections were stained with $2 \%$ aqueous uranyl acetate for 3-5 min and embedded in polyvinyl alcohol (9-10 kDa; Aldrich). The specimens were examined and photographed in a Zeiss CEM 902 electron microscope at $80 \mathrm{kV}$. Quantitative analysis was carried out by photographing random areas covering the BR loci. These areas contained portions from multiple BR transcription units. The frequency of proximal, middle, and distal portions in the material analyzed was equivalent. The number of gold markers in the proximal, middle, and distal segments of the BR genes was counted, and the percentage in each segment was calculated. Results from two independent experiments were pooled.

\section{Nuclear run-on transcription}

Nuclei from C. tentans cells were isolated as described (Percipalle et al. 2003) and permeabilized with $0.2 \%$ Triton X-100 for $3 \mathrm{~min}$ at room temperature. The permeabilized nuclei were resuspended in $100 \mu \mathrm{L}$ of reaction buffer $(20 \mathrm{mM}$ Tris at $\mathrm{pH} 7.9$, $20 \%$ glycerol, $140 \mathrm{mM} \mathrm{KCl}, 5 \mathrm{mM} \mathrm{MgCl}$, 5 mM DTT, $0.015 \%$ sarkosyl and $1 \mathrm{U} / \mu \mathrm{L}$ RNase inhibitor) and incubated with antibodies (final concentration $100 \mu \mathrm{g} / \mathrm{mL}$ ) for $20 \mathrm{~min}$ at room temperature. Two different anti-p2D10 antibodies (mAbs 2D10 and 1F2) and two control antibodies (mAbs $2 \mathrm{~B} 4$ and 6C10) against $C$. tentans nuclear proteins of 40 and $35 \mathrm{kDa}$, respectively, were assayed in parallel. These control $\mathrm{mAbs}$ originate from the same fusions as the anti-p2D10 mAbs and have been produced and treated in parallel (Sabri et al. 2002). Reactions were started by the addition of ATP, CTP, GTP (1 mM each), and $20 \mu \mathrm{Ci}$ $\left[{ }^{32} \mathrm{P}\right] \mathrm{UTP}(3000 \mathrm{Ci} / \mathrm{mM})$. The reactions were allowed to proceed for $20 \mathrm{~min}$ at $37^{\circ} \mathrm{C}$. The RNA was extracted with acid phenol and chloroform, precipitated with ethanol, and resolved in ureapolyacrylamide gels, following standard procedures. The run-on transcription corresponding to pre-mRNA was estimated by quantifying by phosphorimaging the radioactivity incorporated into RNA molecules of length 200 to $700 \mathrm{nt}$ (PhosphorImager; Molecular Dynamics).

\section{Acknowledgments}

We thank Mona Tibäck and Inger Granell for technical assistance, and Örjan Wrange and Piergiorgio Percipalle for critical 
reading of the manuscript. We also thank Piergiorgio Percipalle for the gift of the anti-actin serum. This research was funded by the Swedish Natural Science Research Council (VR-NT), the Swedish Cancer Society, the Carl Tryggers Foundation, and the Åke Wiberg Foundation. E.S. is supported by the Stockholm Graduate School in Genomics and Bioinformatics.

\section{References}

Alzhanova-Ericsson, A.T., Sun, X., Visa, N., Kiseleva, E., Wurtz, T., and Daneholt, B. 1996. A protein of the SR family of splicing factors binds extensively to exonic Balbiani ring premRNA and accompanies the RNA from the gene to the nuclear pore. Genes \& Dev. 10: 2881-2893.

Beermann, W. 1973. Directed changes in the pattern of Balbiani ring puffing in Chironomus: Effects of a sugar treatment. Chromosoma 41: 297-326.

Bettinger, B.T., Gilbert, D.M., and Amberg, D.C. 2004. Actin up in the nucleus. Nat. Rev. Mol. Cell. Biol. 5: 410-415.

Daneholt, B. 2001. Assembly and transport of a premessenger RNP particle. Proc. Natl. Acad. Sci. 98: 7012-7017.

Emili, A., Shales, M., McCracken, S., Xie, W., Tucker, P.W., Kobayashi, R., Blencowe, B.J., and Ingles, C.J. 2002. Splicing and transcription-associated proteins PSF and $\mathrm{p} 54^{\mathrm{nrb}} / \mathrm{nonO}$ bind to the RNA polymerase II CTD. RNA 8: 1102-1111.

Fong, Y.W. and Zhou, Q. 2001. Stimulatory effect of splicing factors on transcriptional elongation. Nature 414: 929-933.

Gallagher, J.E.G., Dunbar, D.A., Granneman, S., Mitchell, B.M., Osheim, Y., Beyer, A.L., and Baserga, S.J. 2004. RNA polymerase I transcription and pre-rRNA processing are linked by specific SSU processome components. Genes \& Dev. 18: 2506-2517.

Gilbert, C., Kristjuhan, A., Winkler, G.S. and Svejstrup, J.Q. 2004. Elongator interactions with nascent mRNA revealed by RNA immunoprecipitation. Mol. Cell 14: 457-464.

Goldstrohm, A.C., Albrecht, T.R., Sune, C., Bedford, M.T., and Garcia-Blanco, M.A. 2001. The transcription elongation factor CA150 interacts with RNA polymerase II and the premRNA splicing factor SF1. Mol. Cell. Biol. 21: 7617-7628.

Hartzog, G.A., Speer, J.L., and Lindstrom, D.L. 2002. Transcript elongation on a nucleoprotein template. Biochim. Biophys. Acta 1577: 276-286.

Hawley, D.K. and Roeder, R.G. 1985. Separation and partial characterization of three functional steps in transcription initiation by human RNA polymerase II. J. Biol. Chem. 260: 8163-8172.

Hofmann, W.A., Stojilikovic, L., Fuchsova, B., Vargas, G.M., Mavrommatis, E., Philimonenko, V., Kysela, K., Goodrich, J.A., Lessard, J.L., Hope, T.J., et al. 2004. Actin is part of pre-initiation complexes and is necessary for transcription by RNA polymerase II. Nat. Cell Biol. 6: 1094-1101.

$\mathrm{Hu}, \mathrm{P} ., \mathrm{Wu}, \mathrm{S}$., and Hernandez, N. 2004. A role for $\beta$-actin in RNA polymerase III transcription. Genes \& Dev. 18: 3010 3015.

Ishitani, K., Yoshida, T., Kitagawa, H., Ohta, H., Nozawa, S., and Kato, S. 2003. p54 ${ }^{\text {nrb }}$ acts as a transcriptional coactivator for activation function 1 of the human androgen. Biochem. Biophys. Res. Commun. 306: 660-665.

Jensen, T.H., Dower, K., Libri, D., and Rosbash, M. 2003. Early formation of mRNP: License for export or quality control? Mol. Cell 11: 1129-1138.

Jenuwein, T. and Allis, C.D. 2001. Translating the histone code. Science 293: 1074-1080.

Kadonaga, J.T. 2004. Regulation of RNA polymerase II transcription by sequence-specific DNA-binding factors. Cell
116: $247-257$.

Khorasanizadeh, S. 2004. The nucleosome: From genomic organization to genomic regulation. Cell 116: 259-272.

Kiesler, E., Miralles, F., Östlund Farrants, A.K., and Visa, N. 2003. The Hrp65 self-interaction is mediated by an evolutionarily conserved domain and is required for nuclear import of Hrp65 isoforms that lack a nuclear localization signal. J. Cell Sci. 116: 3949-3956.

Kornberg, R.D. and Lorch, Y. 1999. Twenty-five years of the nucleosome, fundamental particle of the eukaryote chromosome. Cell 98: 285-294.

Kukalev, A., Nord, Y., Palmberg, C., Bergman, T., and Percipalle, P. 2005. Actin and hnRNP U cooperate for productive transcription by RNA polymerase II. Nat. Struct. Molec. Biol. 12: 238-244.

Kundu, T.K., Wang, Z., and Roeder, R.G. 1999. Human TFIIIC relieves chromatin-mediated repression of RNA polymerase III transcription and contains an intrinsic histone acetyltransferase activity. Mol. Cell. Biol. 19: 1605-1615.

Kwek, K.Y., Murphy, S., Furger, A., Thomas, B., O'Gorman, W., Kimura, H., Proudfoot, N.J., and Akoulitchev, A. 2002. U1 snRNA associates with TFIIH and regulates transcriptional initiation. Nat. Struct. Biol. 9: 800-805.

Ladurner, A.G., Inouye, C., Jain, R., and Tjian, R. 2003. Bromodomains mediate an acetyl-histone encoded antisilencing function at heterochromatin boundaries. Mol. Cell 11: 365376.

Li, Y., Björklund, S., Kim, Y.J., and Kornberg, R.D. 1996. Yeast RNA polymerase II holoenzyme. Methods Enzymol. 273: 172-175.

Maniatis, T. and Reed, R. 2002. An extensive network of coupling among gene expression machines. Nature 416: 499506.

Manley, J.L. 2002. Nuclear coupling: RNA processing reaches back to transcription. Nat. Struct. Biol. 9: 790-791.

Martens, J.H.A., Verlaan, M., Kalkhoven, E., Dorsman, J.C., and Zantema, A. 2002. Scaffold/matrix attachment region elements interact with a p300-Scaffold attachment factor A complex and are bound by acetylated nucleosomes. Mol. Cell. Biol. 22: 2598-2606.

Matangkasombut, O. and Buratowski, S. 2003. Different sensitivities of bromodomain factors 1 and 2 to histone H4 acetylation. Mol. Cell 11: 353-363.

Mathur, M., Tucker, P.W., and Samuels, H.H. 2001. PSF is a novel corepressor that mediates its effect through Sin3A and the DNA binding domain of nuclear hormone receptors. Mol. Cell. Biol. 21: 2298-2311.

Matsutani, S. 2004. Similarities in transcription factor IIIC subunits that bind to the posterior regions of internal promoters for RNA polymerase III. BMC Evol. Biol. 4: 26-32.

Meyer, B., Mähr, R., Eppenberger, H.M., and Lezzi, M. 1983. The activity of Balbiani rings 1 and 2 in salivary glands of Chironomus tentans larvae under different modes of development and after pilocarpine treatment. Dev. Biol. 98: 265277.

Miralles, F., Öfverstedt, L.G., Sabri, N., Aissouni, Y., Hellman, U., Skoglund, U., and Visa, N. 2000. Electron tomography reveals posttranscriptional binding of pre-mRNPs to specific fibers in the nucleoplasm. J. Cell Biol. 148: 271-282.

Moqtaderi, Z. and Struhl, K. 2004. Genome-wide occupancy profile of the RNA polymerase III machinery in Saccharomyces cerevisiae reveals loci with incomplete transcription complexes. Mol. Cell. Biol. 24: 4118-4127.

Myers, L.C., Lacomis, L., Erdjument-Bromage, H., and Tempst, P. 2002. The yeast capping enzyme represses RNA polymerase II transcription. Mol. Cell 10: 883-894. 
Narlikar, G.J., Fan, H.Y., and Kingston, R.E. 2002. Cooperation between complexes that regulate chromatin structure and transcription. Cell 108: 475-487.

Neugebauer, K.M. 2002. On the importance of being co-transcriptional. J. Cell Sci. 115: 3865-3871.

Olave, I.A., Reck-Peterson, S.L., and Crabtree, G.R. 2002. Nuclear actin and actin-related proteins in chromatin remodelling. Annu. Rev. Biochem. 71: 755-781.

Pederson, T. and Aebi, U. 2003. Actin in the nucleus: What form and what for? J. Struct. Biol. 140: 3-9.

Percipalle, P., Zhao, J., Pope, B., Weeds, A., Lindberg, U., and Daneholt, B. 2001. Actin bound to the heterogeneous nuclear ribonucleoprotein hrp36 is associated with Balbiani ring mRNA from the gene to polysomes. J. Cell Biol. 153: 229-236.

Percipalle, P., Jonsson, A., Nashchekin, D., Karlsson, C., Bergman, T., Guialis, A., and Daneholt B. 2002. Nuclear actin is associated with a specific subset of hnRNP A/B-type proteins. Nucleic Acids Res. 30: 1725-1734.

Percipalle, P., Fomproix, N., Kylberg, K., Miralles, F., Björkroth, B., Daneholt, B., and Visa, N. 2003. An actin-ribonucleoprotein interaction is involved in transcription by RNA polymerase II. Proc. Natl. Acad. Sci. 100: 6475-6480.

Philimonenko, V.V., Zhao, J., Iben, S., Dingova, H., Kysela, K., Kahle, M., Zentgraf, H., Hofmann, W.A., de Lanerolle, P., Hozak, P., et al. 2004. Nuclear actin and myosin I are required for RNA polymerase I transcription. Nat. Cell Biol. 6: $1165-1172$.

Proudfoot, N.J., Furger, A., and Dye, M.J. 2002. Integrating mRNA processing with transcription. Cell 108: 501-512.

Reed, R. 2003. Coupling transcription, splicing and mRNA export. Curr. Opin. Cell Biol. 15: 326-331.

Sabri, N., Östlund Farrants, A.K., Hellman, U., and Visa, N. 2002. Evidence for a post-transcriptional role of a TFIIIC $\alpha$ like protein in Chironomus tentans. Mol. Biol. Cell 13: 17651777.

Schramm, L. and Hernandez, N. 2002. Recruitment of RNA polymerase III to its target promoters. Genes \& Dev. 16: 2593-2620.

Schroeder, S., Zorio, D., Schwer, B., Shuman, S., and Bentley, D. 2004. A function of yeast mRNA Cap methyltransferase, Abd1, in transcription by RNA polymerase II. Mol. Cell 13: $377-387$.

Sewer, M.B. and Waterman, M.R. 2002. Transcriptional complexes at the CYP17 CRS. Endocr. Res. 28: 551-558.

Shav-Tal, Y. and Zipori, D. 2002. PSF and p54 $4^{\text {nrb }} /$ NonO-multifunctional nuclear proteins. FEBS Lett. 531: 109-114.

Shivaswamy, S., Kassavetis, G.A., and Bhargava P. 2004. Highlevel activation of transcription of the yeast U6 snRNA gene in chromatin by the basal RNA polymerase III transcription factor TFIIIC. Mol. Cell. Biol. 24: 3596-3606.

Sims III, R.J., Belotserkovskaya, R., and Reinberg, D. 2004. Elongation by RNA polymerase II: The short and long of it. Genes \& Dev. 18: 2437-2468.

Skoglund, U., Andersson, K., Björkroth, B., Lamb, M.M., and Daneholt, B. 1983. Visualization of the formation and transport of a specific hnRNP particle. Cell 34: 847-855.

Svejstrup, J.Q. 2004. The RNA polymerase II transcription cycle: Cycling through chromatin. Biochim. Biophys. Acta 1677: 64-73.

Visa, N. 2005. Actin in transcription. Actin is required for transcription by all three RNA polymerases in the eukaryotic cell nucleus. EMBO Rep. 6: 218-219.

Wang., K. and Richards, F.M. 1974. An approach to nearest neighbor analysis of membrane proteins. Application to the human erythrocyte membrane of a method employing cleav- able cross-linkages. J. Biol. Chem. 249: 8005-8018.

Wieslander, L. 1994. The Balbiani ring multigene family: Coding repetitive sequences and evolution of a tissue-specific cell function. Prog. Nucleic Acid Res. Mol. Biol. 48: 275313.

Wyss, C. 1982. Chironomus tentans epithelial cell lines sensitive to ecdysteroids, juvenile hormone, insulin and heat shock. Exp. Cell Res. 139: 297-307.

Zhang, S., Buder, K., Burkhardt, C., Schlott, B., Gorlach, M., and Grosse, F. 2002. Nuclear DNA helicase II/RNA helicase A binds to filamentous actin. J. Biol. Chem. 277: 843-853.

Zhao, K., Wang, W., Rando, O.J., Xue, Y., Swiderek, K., Kuo, A., and Crabtree, G.R. 1998. Rapid and phosphoinositol-dependent binding of the SWI/SNF-like BAF complex to chromatin after T lymphocyte receptor signaling. Cell 95: 625-636.

Zorio, D.A.R. and Bentley, D.L. 2004. The link between mRNA processing and transcription: Communication works both ways. Exp. Cell Res. 296: 91-97. 


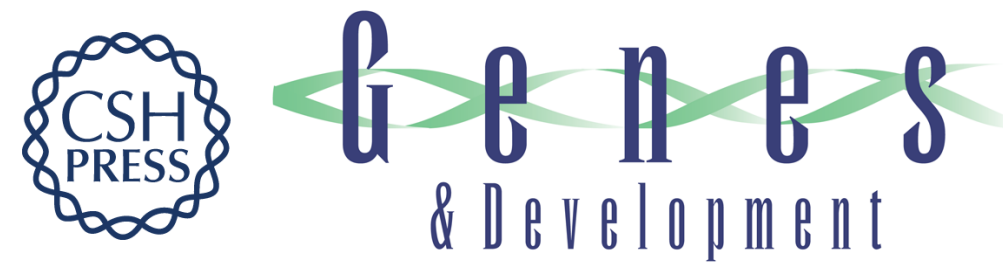

\section{The growing pre-mRNA recruits actin and chromatin-modifying factors to transcriptionally active genes}

Mikael Sjölinder, Petra Björk, Emilia Söderberg, et al.

Genes Dev. 2005, 19:

Access the most recent version at doi:10.1101/gad.339405

References This article cites 60 articles, 23 of which can be accessed free at: http://genesdev.cshlp.org/content/19/16/1871.full.html\#ref-list-1

License

Email Alerting

Receive free email alerts when new articles cite this article - sign up in the box at the top Service right corner of the article or click here.

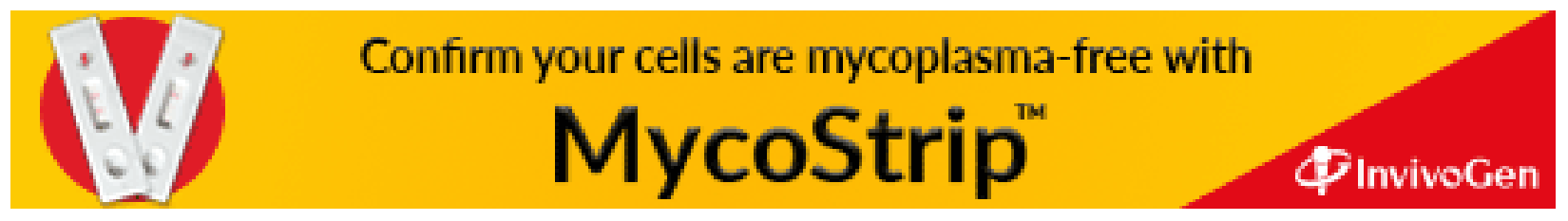

